\title{
Examination of the Risk Assessment Levels of Athletes in Different Branches According to Some Variables
}

\author{
Abdurrahman Kirtepe \\ Correspondence: Abdurrahman Kirtepe, Frrat University, Faculty of Sports Sciences, Turkey.
}

Received: August 15, 2018

doi:10.11114/jets.v6i10.3540

\author{
Accepted: September 16, $2018 \quad$ Online Published: September 17, 2018 \\ URL: https://doi.org/10.11114/jets.v6i10.3540
}

\begin{abstract}
In this study, the risk assessment levels of athletes in different branches were examined in terms of various variables. Descriptive scanning model was used in the study. In the research, the survey was completed with a sample method of 105 people. The questionnaire was used as a data collection tool in the research. The questionnaire consists of questions about personal information and the Risk Assessment scale for athletes and coaches. Data analysis was performed in SPSS 21 package program. Descriptive statistics such as frequency, percent, and mean, standard deviation, minimum and maximum were used in data analysis. Data analysis was performed in SPSS 21 package program. Descriptive statistics such as frequency, percent, and mean, standard deviation, minimum and maximum were used in data analysis. As a result of the research, it was determined that the risk assessment perceptions of athletes according to their age, branches, educational status and income status did not differ. As a result of the research, it was determined that the risk assessment perceptions of athletes according to their age, branches, educational status and income status did not differ.
\end{abstract}

Keywords: sports, risk, risk assessment

\section{Introduction}

Although all measures are taken in all sports branches with recreational activities, there are always some risks. For this reason, fans, athletes and coaches face many dangers that may arise due to lighting, floor and material (Nohr, 2009). Risk factors vary in each sport activity. In addition to factors such as athletes, materials used in sports, sports branch, features of materials, environment conditions in sports, lack of adequate facilities and materials, and many factors such as cold and rainy weather cause athletes to face some risks(Bağrıç̧ık,2005;Çobanoğlu,2008). Sports injuries and rehabilitation. Risk management in sports is the assessment of the risk factors that may arise from security audits in a sports program (Çobanoğu, 2013). It is necessary to minimize or eliminate the death, injury and possible situations that may arise during risk management, reaction and sports activities (Spengler at.all.2006). The aim of this study is to investigate the risk assessment levels of athletes in different branches in terms of various variables.

\subsection{Perception of Risk Taking}

In a risky situation, the person's decision-making behavior is called risk-taking behavior. The fundamental element of risk is uncertainty. The results of decisions taken or taken may be positive or negative. The expected result is positive or negative and the possible size of the result will affect the decision making process (Çobanoğlu, 2013). Taking risks may include behaviors that may cause fatal consequences in some cases, but have positive side effects. In this regard, some precautions and precautions are required. This behavior has to be based on data in order to be rational to take risks. Benefiting from experienced individuals, relying on research, planning is important in terms of analyzing losses. It is important to know clearly that the presence of a person in a trial will not lead to loss of life. There is a certain risk in almost every aspect of life. In this context, people should not take risks that they cannot bear or carry. The risks that a person does in order to benefit from life and health can be encouraged (Y1lmaz, 2000). Statistics do not provide much benefit in identifying People's risk-taking behavior. In different situations people can exhibit different attitudes and behaviors. The risk behaviors of individuals who work with work or who are exposed to time pressures are evaluated as normal behaviors and decisions about whether or not risky behavior will occur in decision-making processes (Everley, 2002)).

\subsubsection{Risk Behavior in Sports}

Sportive lifestyle affects the biomotoric, physical, cognitive, physiological and psychological characteristics of athletes. In this context, performance is generally a limited and short-term segment of attitudes and behavior. Performance can be 
expressed as an action to perform a particular business or activity. In other words, performance can be defined as the psychological, physiological and biomotoric efficiency of physical activity. The performance, which is understood from the definitions, is the level of productivity that the athlete clearly exhibits as psychological, physical, biomotoric and physiologically. The performance levels of individuals throughout their lives are constantly changing. This is a natural consequence of change. However, many risk factors influence this change in question (Karakuş, 2006; Engebretsen, 2012; Acar, 2016; Açar, 2017).There are many internal and external factors that influence the success of sports facilities. Depending on these factors, positive or negative or sometimes positive or negative results can be revealed. Events with negative content in sports pose risks. Basically, there are four main risk groups that arise due to the structure of sports clubs and activities in which sports teams are involved. These groups are as follows (Çobanoğlu, 2008; Abraham, 2013).

- Field: the team's work or has the lack of sports fields, lack of lighting, the field does not have a safe environment, cleanliness, such as factors are a source of risk in terms of the team's goals.

- Equipment and Materials: the sports activity coaches, athletes and other persons used by the sports services to provide the equipment and materials used by clubs in the purpose of providing. The lack of control and maintenance of these items may be a risk source.

- Program: problems arise in terms of time, cost, technical and chart risk detection and management in order to provide access to the objectives of the plans and programs prepared within the scope of the goals of sports clubs and teams.

- People: this group includes coaches, athletes, sharers, fans and volunteers. The attitudes and behaviors of each person in this group are unpredictable and they can cause problems in fulfilling their duties and responsibilities, but they can also make mistakes. This is why it is considered as a risk factor for human factor.

\section{Method}

\subsection{Type of Research}

Descriptive scanning model was used in the study.

\subsection{Universe and Sample}

The universe of the research is formed by athletes in different branches of Elazig. In the research, the survey was completed with a sample method of 105 people.

\subsection{Data Collection Tool}

The questionnaire was used as a data collection tool in the research. The questionnaire consists of questions about personal information and the Risk Assessment scale for athletes and coaches. Risk Assessment scale for athletes and coaches: the risk assessment scale developed by Karatas (2012) includes how risky it is for athletes and coaches to evaluate the questions on the scale. Scale materials (Gök, 2006; Çobanoğlu, 2008) were prepared using the study. Factor analysis revealed that some substances with a low factor load or taking a high factor load value from multiple factors were removed from the scale. As a result of repeated factor analysis, the scale consists of 23 items. The answers are scored according to the type of 5 likert, the items are "very little-1, less-2, medium-3, very- 4 , very much-5".Total scale a 4-factor structure; the first factor is located in (1.2.3.4.5.6.7.8) substances related to health management, located in the second factor (9.10.11.12.13) substances related to management of the facility, located in the third factor (14.15.16.17.18.19) substances related to the financial management of the fourth factor is located in (20.21.22.23) risk assessment of substances was comprised of in relation to the elements of the Social Security Administration was observed.

\subsection{Data Analysis}

Data analysis was performed in SPSS 21 package program. Descriptive statistics such as frequency, percent, mean, standard deviation, minimum and maximum were used in data analysis. In addition, $t$ test and ANOVA test were used to determine the relationship between personal information and risk assessment perception for athletes and coaches. Kolmogorov Smirnov test was used in the selection of these tests. The t-test and ANOVA test were determined to provide the normality assumption of all sub-dimensions and the parametric tests were decided to be performed. 


\section{Findings and Comments}

Table 1. Findings of Personal Information

\begin{tabular}{|c|c|c|}
\hline \multirow{2}{*}{\multicolumn{3}{|c|}{ Gender }} \\
\hline & & \\
\hline Man & 56 & 53,3 \\
\hline Woman & 49 & 46,7 \\
\hline \multicolumn{3}{|l|}{ Old } \\
\hline 21 to 30 years old & 54 & 51,4 \\
\hline $31-40$ years & 39 & 37,1 \\
\hline Age 41 and over & 12 & 11,4 \\
\hline \multicolumn{3}{|l|}{ Condition } \\
\hline Married & 61 & 58,1 \\
\hline Single & 44 & 41,9 \\
\hline \multicolumn{3}{|l|}{ Your branch } \\
\hline Football & 22 & 21,0 \\
\hline Basketball & 26 & 24,8 \\
\hline Volleyball & 37 & 35,2 \\
\hline Handball & 20 & 19,0 \\
\hline \multirow{2}{*}{\multicolumn{3}{|c|}{ High }} \\
\hline & & \\
\hline & 67 & 63,8 \\
\hline Graduate & 21 & 20,0 \\
\hline \multicolumn{3}{|l|}{ Income Status } \\
\hline 1001-2000 & 10 & 9,5 \\
\hline 2001-3000 & 44 & 41,9 \\
\hline $3001-4000$ & 38 & 36,2 \\
\hline 4001-5000 & 13 & 12,4 \\
\hline
\end{tabular}

Among the surveyed, $53.3 \%$ were male and $51.4 \%$ were male, between $21-30$ years, $58.1 \%$ were married, $35.2 \%$ were sports in volleyball branch, $63,8 \%$ were university graduates and $41.9 \%$ of the income was between 2001 and 3000tl.

Table 2. Findings for Risk Assessment scale for athletes and coaches

\begin{tabular}{lcrrrrr}
\hline & N Mini mum & \multicolumn{2}{c}{ MaksimumOrt } & Std ss. & K-S Z & p \\
\hline Health Management & 10521,00 & 40,00 & 31,50 & 4,44 & 0,714 & 0,688 \\
Plant Management & 10515,00 & 25,00 & 20,77 & 2,39 & 1,085 & 0,190 \\
Finance Management 10519,00 & 30,00 & 26,04 & 2,39 & 1,115 & 0,166 \\
Social Security & 10513,00 & 20,00 & 17,88 & 1,80 & 1,215 & 0,123 \\
\hline
\end{tabular}

The results of the Kolmogorov Smirnov test for the lower dimensions of the Risk Assessment scale for athletes and coaches were analyzed and it was determined that all dimensions provide a normal distribution assumption ( $\mathrm{P}>0.05)$. This indicates that the $t$ test and the ANOVA test will give reliable results. 
Table 3. Risk assessment for athletes and coaches according to personal information

\begin{tabular}{|c|c|c|c|c|}
\hline \multirow{2}{*}{ Healthcare } & \multirow[b]{2}{*}{ Facility } & \multicolumn{3}{|c|}{ Average \pm Std. Deviation } \\
\hline & & & & \\
\hline $\begin{array}{c}\text { Management } \\
\end{array}$ & \multicolumn{2}{|l|}{ Management } & \multicolumn{2}{|c|}{ Management security } \\
\hline Cinsiyet Man & $31,66 \pm 3,87$ & $20,82 \pm 2,35$ & $26,66 \pm 2,10$ & $18,19 \pm 1,58$ \\
\hline Woman & $31,32 \pm 5,06$ & $20,71 \pm 2,44$ & $25,34 \pm 2,52$ & $17,53 \pm 1,98$ \\
\hline $\mathbf{t}$ & 0,382 & 0,228 & 2,907 & 1,910 \\
\hline $\mathbf{p}$ & 0,703 & 0,820 & 0,004 & 0,059 \\
\hline \multicolumn{5}{|l|}{ Old } \\
\hline 21 to 30 years old & $31,14 \pm 4,38$ & $20,79 \pm 2,35$ & $25,79 \pm 2,59$ & $17,64 \pm 1,86$ \\
\hline $31-40$ years & $32,23 \pm 4,79$ & $20,87 \pm 2,51$ & $26,69 \pm 2,19$ & $18,12 \pm 1,74$ \\
\hline Age 41 and over & $30,75 \pm 3,44$ & $20,33 \pm 2,26$ & $25,08 \pm 1,50$ & $18,16 \pm 1,69$ \\
\hline $\mathbf{F}$ & 0,863 & 0,235 & 2,783 & 0,965 \\
\hline p & 0,425 & 0,791 & 0,067 & 0,384 \\
\hline \multicolumn{5}{|l|}{ Condition } \\
\hline Married & $31,80 \pm 4,70$ & $20,86 \pm 2,49$ & $26,57 \pm 2,31$ & $18,03 \pm 1,73$ \\
\hline Single & $31,09 \pm 4,09$ & $20,63 \pm 2,26$ & $25,31 \pm 2,32$ & $17,68 \pm 1,90$ \\
\hline $\mathbf{t}$ & 0,808 & 0,490 & 2,736 & 0,983 \\
\hline $\mathbf{p}$ & 0,421 & 0,628 & $\mathbf{0 , 0 0 7}$ & 0,328 \\
\hline \multicolumn{5}{|l|}{ Your branch } \\
\hline Football & $31,40 \pm 4,76$ & $20,68 \pm 2,35$ & $26,36 \pm 2,10$ & $18,00 \pm 2,16$ \\
\hline Basketball & $30,30 \pm 4,64$ & $20,34 \pm 2,52$ & $25,76 \pm 2,58$ & $18,15 \pm 1,66$ \\
\hline Volleyball & $31,40 \pm 4,50$ & $21,05 \pm 2,44$ & $25,83 \pm 2,38$ & $17,37 \pm 1,73$ \\
\hline Handball & $33,35 \pm 3,28$ & $20,90 \pm 2,22$ & $26,45 \pm 2,52$ & $18,35 \pm 1,56$ \\
\hline F & 1,827 & 0,469 & 0,522 & 1,669 \\
\hline p & 0,147 & 0,705 & 0,668 & 0,179 \\
\hline \multicolumn{5}{|l|}{$\frac{P}{\text { Education Status }}$} \\
\hline High school & $30,29 \pm 5,15$ & $21,41 \pm 2,76$ & $25,29 \pm 2,84$ & $17,52 \pm 1,97$ \\
\hline University & $31,97 \pm 4,12$ & $20,61 \pm 2,23$ & $26,13 \pm 2,32$ & $18,05 \pm 1,60$ \\
\hline Graduate & $31,00 \pm 4,82$ & $20,76 \pm 2,58$ & $26,38 \pm 2,20$ & $17,61 \pm 2,24$ \\
\hline F & 1,134 & 0,755 & 1,094 & 0,870 \\
\hline $\mathbf{p}$ & 0,326 & 0,472 & 0,339 & 0,422 \\
\hline \multicolumn{5}{|l|}{ Income Status } \\
\hline $1001-2000$ & $31,90 \pm 4,72$ & $20,40 \pm 3,02$ & $26,60 \pm 2,22$ & $18,10 \pm 1,96$ \\
\hline 2001-3000 & $30,81 \pm 4,76$ & $21,02 \pm 2,49$ & $26,25 \pm 2,81$ & $17,88 \pm 1,97$ \\
\hline $3001-4000$ & $31,84 \pm 4,37$ & $20,65 \pm 2,24$ & $25,92 \pm 2,07$ & $17,81 \pm 1,62$ \\
\hline $4001-5000$ & $32,53 \pm 3,33$ & $20,53 \pm 2,10$ & $25,30 \pm 1,79$ & $17,92 \pm 1,75$ \\
\hline F & 0,676 & 0,306 & 0,727 & 0,066 \\
\hline $\mathbf{p}$ & 0,569 & 0,821 & 0,538 & 0,978 \\
\hline
\end{tabular}

When the perception of risk assessment for sportsmen and coaches according to personal information was examined, financial management perception varies according to sex and marital status $(p<0.05)$; it was found that there was no statistically significant relationship between other sub-dimensions and personal information ( $p>0.05$ ).In financial management perception, the perception of men $(26,66 \pm 2,10)$ is higher than that of females $(25,34 \pm 2,52)$. Again, the perception of married people $(26,57 \pm 2,31)$ is higher than that of cigarettes $(25,31 \pm 2,32)$. According to female athletes of male athletes, marital athletes have higher financial management risk perceptions than single athletes.

\section{Result}

The most important thing in sport is to be successful. Each coach and coach works for success and undertake various risks. However, athletes need to determine the risks correctly in order to achieve their goals and be aware of situations that can make them difficult in the face of risk levels. It is important for athletes to determine the best risk factors in order to minimize injuries, failures, dissatisfactions or economic distress. In this study, the risk assessment levels of athletes in different branches were examined in terms of various variables. As a result of the research, it was determined that the risk assessment perceptions of athletes according to their age, branches, educational status and income status did not differ. However, according to gender and marital status, only financial management differs statistically from risk perception. Financial management risk perceptions of male athletes compared to female athletes and married athletes compared to single athletes were higher. The higher the financial responsibilities of male athletes and married athletes towards their families, the higher the risk perceptions of financial management.

\section{Reference}

Abrahams, S., Mc Fie, S., Patricios, J., Posthumus, M., \& September, A. V. (2013). Risk factors for sports concussion: an evidence-based systematic review. Br. J. Sports Med.

Açar, B., \& Kara, M. (2017). Sudden Cardiac Death in Sports: Current Approaches in Clinical Practice. Sports Medicine Journal, 52(1), 014-024.

Acar, E., Demir, A., Kılınç, C. Y., Yıldırım, B., \& Beydilli, H. (2016). Injuries of winter sports. Muğla Sıtkı Koçman 
University Medical Journal / Mugla Medical Journal, 3(1), 29-33.

Bağrıaçı, A., \& Açak, M. (2005). Sports injuries and rehabilitation. Yaylacık Printing House, Istanbul.

Çobanoğlu, H. O. (2008). Risk management in sports. A Research on the Risk Assessment of Sportsmen in Turkcell Super League. Graduate Thesis, Anadolu University Institute of Health Sciences Department of Physical Education and Sport, Eskişehir.

Çobanoğlu, H. O., \& Sevil, G. (2013). Risk managementin sports. A Research on Risk Assessments of Top Footballers, CBÜ Physical Education and Sports Science Journal, 8(2), 1-15.

Engebretsen, L., Soligard, T., Steffen, K., Alonso, J. M., Aubry, M., Budgett, R., \& Palmer-Green, D. (2012). Sports injuries and illnesses during the London Summer Olympic Games. Br. J. Sports Med., 47(7), 407-414. https://doi.org/10.1136/bjsports-2013-092380

Everley, M. J. (2002). The Ethical Aspects of Risk Assessment in the Field of Occupational Safety and Health. Cite seer.

Gök, Y. (2006). Turkey evaluation of the risk management of sports clubs in the first league volleyball. Master Thesis. Ankara University, Institute of Health Sciences, Ankara.

Karakuş, S., \& Kilinc, F. (2006). Posture and Sportive Performance. Kastamonu Education Journal, 14, 309-322.

Karataş, Ö. (2012). Risk management in sports. Turkey Handball Super League Example, Firat University Institute of Health Sciences, Elazig.

Nohr, K. M. (2009). Managing risk in sport and recreation. IL: Human Kinetics.

Spengler, J. O., Connaught on, D. P., \& Pittman, A. T. (2006). Risk management in sport and recreation. Human Kinetics, United States, 2-9, 12-20.

Yılmaz, T. (2000). Investigation of Risk Taking Behaviors in Adolescents. Social Sciences Institute. Master's Thesis, Izmir: Ege University.

\section{Copyrights}

Copyright for this article is retained by the author(s), with first publication rights granted to the journal.

This is an open-access article distributed under the terms and conditions of the Creative Commons Attribution license which permits unrestricted use, distribution, and reproduction in any medium, provided the original work is properly cited. 